\title{
TAV of English Finite Verb Phrase
}

\author{
Peter Lung-shan CHUNG \\ University of Hong Kong, Hong Kong, China
}

\begin{abstract}
It is widely known that a finite verb phrase (fVP) of a clause in English consists of three components: tense, aspect and voice. While the two tenses, present and past, and the two voices, active and passive, are recognized and generally agreed, the number and constituents of aspects may not be so simple and they are open to dispute. This paper proposes that a new aspect, the "modal" aspect, be included in addition to the commonly recognized ones, namely "simple”, "perfect” and “continuous” (also known as "progressive”). With the inclusion of the "modal” aspect, there are four single aspects: “simple”, “modal”, "perfect” and “continuous”. They can be combined to form multiple aspects according to the aforesaid sequence. The "modal" aspect is realized with a modal verb (any ofthe modal verbs will/would, shall/should, can/could, may/might, must, ought to, used to and the two semi-modals, “need" and "dare” in interrogative and negative structures). Whenever a modal verb is used, the verb phrase is in the modal aspect. The modal verb to be used is for the interlocutor to decide and falls beyond this discussion, which focuses on the structure of the fVP of the English language. The two tenses, eight aspects and two voices (active and passive) make up the 32 TAVs (an acronym formed with “Tense”, “Aspect” and "Voice”) of the English fVP. The "discovery" of the "modal" aspect and its incorporation in the aspect system of English might have a significant impact on the learning of English for non-native speakers as they would have a clearer and more precise concept about the "TAVs" of the English fVP.
\end{abstract}

Keywords: English verb phrase, finite verb phrase, tense, aspect, mood, modality, modal verb, TAV

\section{Introduction}

It is widely known that a finite verb phrase (fVP) of a clause in English consists of three components: tense, aspect and voice. While the two tenses, present and past, and the two voices, active and passive, are recognized and generally agreed to, the number and constituents of aspects may be open to dispute.

This paper proposes that a new aspect, the "modal" aspect, be included in addition to the commonly recognized ones, namely "simple”, "perfect” and "continuous” (also known as "progressive”). With the inclusion of the "modal” aspect, there are four single aspects: "simple”, "modal”, "perfect” and "continuous”. They can be combined to form another four multiple aspects in the aforesaid sequenceexcept the "simple" aspect, which is mutually exclusive with the other three.

Peter Lung-shan CHUNG, B.A., M.A., PhD University of Hong Kong, Former Chief Translation Officer of the Hong Kong Special Administrative Region of People's Republic of China 
The establishment of the "modal" aspect and its incorporation in the aspect system of English might have a significant impact on the learning of English for non-native speakers as they would have a clearer and more precise concept about the "TAVs" of the English finite verb phrases.

\section{Discussion}

\section{The Two Tenses}

It should be noted that there are only two tenses in English: the present tense and the past tense. While three or four time-notions (past, present and future, or four with the "no time" which refers to generality of unlimited time) are recognized, the English finite verb phrases are expressed with two tenses only: present and past. The future "time" is generally indicated with the present tense in various aspects. Here are some examples:

(a) When he comes tomorrow, he will meet us.

(b) We are flying to London on Friday.

(c) They are not giving us any more help in the future.

The time in each sentence is future while the present simple "comes" is used in the time clause of (a) and the present modal "will meet" is used in the main clause. In (b), the present continuous "are flying" is used to indicate that arrangements have been made for the trip. The present continuous "are not giving" in (c) shows that the speaker is quite sure of it.

Hence it can be said that the present tense is used for "no time", "present time" and "future time".

Moreover, the past tense is generally used for past time although it can also be used to show impossibility, unlikeness or politeness if the time reference is the present or the future.

\section{Modality as an Aspect in the English fVP}

Tense-aspect-mood, commonly abbreviated TAMand alsoknown as tense-modality-aspect or TMA, has beenidentified as the grammatical system of a language that covers the expression of tense (location in time), aspect (fabric of time-a single block of time, continuous flow of time, or repetitive occurrence), and mood or modality (degree of necessity, obligation, probability, ability). ${ }^{1}$

In the context of English finite verb phrases (fVP), however, it is argued that modality can be treated as an aspect. If we focus on the sequence of expression in an fVP, we find that the modality or lack of it is shown before other aspects, namely "simple", "perfect" and "continuous". For example, in the fVP "He may have left", the modal verb "may" comes first, showing that the fVP is in present tense and perfect aspect. In another fVP "He might have been punished", the "might' shows that the fVP is in past tense, perfect aspect and passive voice. And in yet another fVP "He smiles", the lack of modal verb shows that it has no 'mood' and is in present tense, simple aspect and active voice. Hence in English, the modality or the lack of it is indicated at the beginning of the fVP and the tense of the verb phrase is reflected in the modal verb if it exists. In other words, the mood of an English verb should not be expressed with TAM.

It is now proposed that modality be treated as an aspect in the fVP of English. While it is disputable whether modality is an "aspect", its being treated so can simplify and systemize the names of English fVP. In my system, there are four single "aspects" in English: "simple”, "modal”, "perfect" and "continuous". The

${ }^{1}$ Bybee, Joan L., Revere Perkins, and William Pagliuca 1994 
"simple" aspect is mutually exclusive with the other three aspects. If a fVP is in the "simple" aspect, it will not go with any other aspects; if the fVP is not in the "simple" aspect, it can be any one or other combinations of the rest. The "modal" aspect refers to a fVP in which a modal verb is used. The other three aspects can stand alone or make combinations in the order of "modal"- "perfect"- "continuous". Altogether there are eight “aspects”: “simple”, “modal”, “perfect”, “continuous”, “modal perfect”, “modal continuous”, "perfect continuous", "modal perfect continuous". This incorporation of 'mood' into the "aspects" of the English fVP can facilitate the teaching of English to students of the language, although whether such incorporation is conceptually correct or appropriate is open to dispute.

\section{The Eight Aspects: Four Single and Four Multiple}

Except for the "simple" aspect, which is mutually exclusive with the others and always stands alone, the other three aspects can be combined in accordance with their hierarchy to give four multiple aspects: "modal perfect”, "modal continuous”, "perfect continuous” and "modal perfect continuous”. Altogether there are eight aspects for the English finite verb phrase: "simple”, “modal”, "perfect”, “continuous”, "modal perfect”, "modal continuous”, "perfect continuous” and "modal perfect continuous”.

The realization of the 'modal' aspect issimple. Whenever a modal verb (the nine groups and thirteen members — will/would, shall/should, can/could, may/might, must, ought to, used to and the two semi-modals, "need" and "dare" in interrogative and negative structures), the verb phrase is in the modal aspect. The modal verb to be used is for the interlocutor to decide as each of the modal verbs implies a certain "mood" or underlying meaning. There has been much discussion on the meanings and suggestions of the modal verbs but this paper merely proposes that the use of a modal verb in a fVP will turn it into the modal aspect.

\section{The Two Voices}

Another point I would like to make is about the "compulsory" indication of voice (active/passive) in the description of an English fVP. For many learners of English, they are taught about passive voice at a later stage of their study of the language but the voice of the verb phrase is an intrinsic part of it. Perhaps it will help learners of English to understand the structure of English verb phrases if they are trained to be conscious about the voice of a verb phrase at an early stage.

It is also found that many learners of English are not clear about the definition for active voice and passive voice. Therefore it should be pointed out that active voice is used when the subject of a FVP is the performer of the main verb (or the logical subject of the verb phrase in a non-finite verb phrase) and passive voice is used when the subject is the recipient of the main verb.

\section{The 32 TAVs of English fVP}

Under my framework, English consists of two tenses (present and past), eight aspects (four single ones and four multiple ones) and two voices (active and passive) for its fVP. Any fVP can be described with its TAV. A full list of the 32 TAVs of the English fVP ( with "drive” as the main verb) is given below.

Active Voice

(1) Present simple—I drive. He drives.

(2) Past simple-You drove. She drove.

(3) Present modal—We shall drive. They may drive. 
(4) Past modal—You should drive. He might drive.

(5) Present perfec - I have driven. She has driven.

(6) Past perfect—We had driven. They had driven.

(7) Present continuous-I am driving. He is driving.

(8) Past continuous-You were driving. They were driving.

(9) Present modal perfect-We may have driven. He must have driven.

(10) Past modal perfect-I might have driven. She would have driven.

(11) Present modal continuous-You will be driving. They will be driving.

(12) Past modal continuous-We would be driving. He might be driving.

(13) Present perfect continuous-I have been driving. She has been driving.

(14) Past perfect continuous-You had been driving. They had been driving.

(15) Present modal perfect continuous - I may have been driving. He may have been driving.

(16) Past modal perfect continuous-I might have been driving. He might have been driving.

\section{Passive voice}

(17) Present simple-I am driven. He is driven.

(18) Past simple-You were driven. She was driven.

(19) Present modal —We shall be driven. They may be driven.

(20) Past modal—You should be driven. He might be driven.

(21) Present perfect—I have been driven. She has been driven.

(22) Past perfect-We had been driven. They had been driven.

(23) Present continuous-I am being driven. He is being driven.

(24) Past continuous-You were being driven. They were being driven.

(25) Present modal perfect-We may have been driven. He must have been driven.

(26) Past modal perfect-I might have been driven. She would have been driven.

(27) Present modal continuous-You will be being driven. They will be being driven.

(28) Past modal continuous - We would be being driven. He might be being driven.

(29) Present perfect continuous - I have been being driven. She has been being driven.

(30) Past perfect continuous-You had been being driven. They had been being driven.

(31) Present modal perfect continuous-I may have been being driven.

(32) Past modal perfect continuous-He might have been being driven.

Altogether, there are 32 TAVs for an English fVP.

\section{Order of the TAV}

The TAV system goes closely with the word order Tense-Aspect-Voice. In any fVP, the first word shows its tenseclearly. It is either the present or past form of an ordinary verb, a modal verb, a verb to "have" or a verb to "be". Then it comes to the aspect(s). If the first word is an ordinary verb, the verb phrase is in the simple aspect; if it is a modal verb, the modal aspect; a verb to "have" followed by a past-participle, the perfect aspect; a verb to 
"be” followed by a present participle, the continuous aspect. The fVP "may have been working” can be labelled with TAV as "present modal perfect continuous active" and "had been promoted" is "past perfect passive".

\section{Conclusion}

It is proposed that there are 32 different structures of the English finite verb phrase:

Two tenses-

(1) present and past;

(2) Past;

Eight aspects (four single and four multiple)—

(1) simple

(2) modal

(3) perfect

(4) continuous

(5) modal perfect

(6) modal continuous

(7) perfect continuous

(8) modal perfect continuous; and

Two voices-

(1) active (when the subject is the performer of the main verb)

(2) passive (when the subject is the recipient of the main verb)

The advantage of the TAV framework is that it is simple and clear while the disadvantage could be its doubtfulness as it is disputable whether the mood of a verb phrases can be regarded as an aspect.

\section{References}

Binnick, R. I. (1991). Time and the verb: A guide to tense and aspect. US: Oxford University Press.

Bybee, J. L., Perkins, R., \& Pagliuca, W. (1994). The evolution of grammar: Tense, aspect, and modality in the languages of the world. US: University of Chicago Press

Fergusson, R. (2011). The complete guide to grammar. London: Arcturus Publishing Limited.

Nordquist, R. (2018). Definition and examples of aspect in English grammar. Retrieved from

https://www.thoughtco.com/what-is-aspect-grammar-1689140

University College London. The Internet Grammar of English. Retrieved from http://www.ucl.ac.uk/internet-grammar/home.htm 